\title{
Attitudes toward genetic testing and personalised nutrition in a representative sample of European consumers
}

\author{
Barbara J. Stewart-Knox ${ }^{1}$, Brendan P. Bunting ${ }^{2}$, Sarah Gilpin ${ }^{1}$, Heather J. Parr ${ }^{1}$, Silvia Pinhão ${ }^{3}$, \\ J. J. Strain ${ }^{1}$, Maria D. V. de Almeida ${ }^{3}$ and Mike Gibney ${ }^{4}$ \\ ${ }^{1}$ Northern Ireland Centre for Food, Health (NICHE), University of Ulster, Coleraine, County Londonderry, UK \\ ${ }^{2}$ School of Psychology, University of Ulster, Coleraine, County Londonderry, UK \\ ${ }^{3}$ University of Porto, Porto, Portugal \\ ${ }^{4}$ University College Dublin, Belfield, Dublin 4, Republic of Ireland
}

(Received 19 December 2007 - Revised 9 July 2008 - Accepted 14 July 2008 - First published online 8 September 2008)

\begin{abstract}
Negative consumer opinion poses a potential barrier to the application of nutrigenomic intervention. The present study has aimed to determine attitudes toward genetic testing and personalised nutrition among the European public. An omnibus opinion survey of a representative sample aged 14-55 + years ( $n$ 5967) took place in France, Italy, Great Britain, Portugal, Poland and Germany during June 2005 as part of the Lipgene project. A majority of respondents $(66 \%)$ reported that they would be willing to undergo genetic testing and $27 \%$ to follow a personalised diet. Individuals who indicated a willingness to have a genetic test for the personalising of their diets were more likely to report a history of high blood cholesterol levels, central obesity and/or high levels of stress than those who would have a test only for general interest. Those who indicated that they would not have a genetic test were more likely to be male and less likely to report having central obesity. Individuals with a history of high blood cholesterol were less likely than those who did not to worry if intervention foods contained GM ingredients. Individuals who were aware that they had health problems associated with the metabolic syndrome appeared particularly favourable toward nutrigenomic intervention. These findings are encouraging for the future application of personalised nutrition provided that policies are put in place to address public concern about how genetic information is used and held.
\end{abstract}

Personalised nutrition: Nutrigenomics: Consumers: Surveys: Attitudes

Nutrigenomics and its application, personalised nutrition, hold potential to revolutionise public health care, health promotion and the food market. If taken up, nutrigenomics could render health the most important driver of consumer food choice ${ }^{(1)}$. As a scientific paradigm, nutrigenomics is in its infancy and so it is uncertain how related developing technologies will be accessed $^{(2)}$ and eventually used by society ${ }^{(3)}$ and the food industry ${ }^{(4)}$ or what sort of impact they will have upon public health $^{(5,6)}$. One anticipated outcome is that foods and dietary interventions could be developed for groups of individuals with specific genotypes. The consumer could then decide whether or not to seek knowledge of their genetic propensity for disease and then whether to make food choices on the basis of this knowledge. Some existing studies have considered public attitudes toward genetic testing in general, while very few have looked at attitudes specifically related to personalised nutrition.

Most existing research into the public view of genetic testing has been qualitative and has taken place in the USA. The American public appear to view genetic testing positively in so far as the information can be used for disease prevention and to enable individuals to take better control over their health $^{(7,8)}$. Although knowledge of genetic disease concepts may be limited among consumers, understanding of potential practical and ethical barriers to the uptake and use of such knowledge appears well developed ${ }^{(9)}$. Qualitative studies conducted in the UK in the wake of controversy surrounding the UK Biobank project have implied a lack of confidence in government ability to regulate the use of genetic information. As the case in the $\operatorname{USA}^{(7,8)}$, concerns surround potential misuse of samples, lack of confidentiality, improper use of information, for example, by insurers and employers, discrimination on the basis of genotype and commercial exploitation of both the information and technology ${ }^{(5,10,11)}$.

One of few existing large population surveys of consumer opinion of genetic testing has indicated that as many as $21 \%$ of consumers in the USA would be unwilling to undergo genetic testing for any reason ${ }^{(12)}$. A survey carried out in the Netherlands indicated more positive attitudes toward genetic testing particularly among those convinced of the usefulness of adapting lifestyle on the basis of genotype ${ }^{(13)}$. Another recent survey also carried out in the Netherlands ${ }^{(14)}$ has suggested that attitudes toward genetic testing were positive among patients with chronic disease particularly among those who were younger and/or more educated. This suggests that further population research into attitudes toward genetic testing would do well to compare the opinion of those who have knowledge that they have a health problem with those who do not.

Only one study appears to have considered opinion of personalised nutrition. A range of stakeholders, including 
scientists, health professionals, food industry and consumer representatives based in the Netherlands were asked as to their views on nutrigenomic issues ${ }^{(6)}$. The main finding was an apparent lack of agreement among experts in regard to the definition of nutrigenomics, its feasibility and practice. It was projected that it would take at least 30 years before personalised nutrition would become normalised and even longer before society could reap any associated public health benefits. Consumer acceptance of nutrigenomic technology and how ethical issues in its application are dealt with were considered important determinants of the future success or failure of this new approach to health promotion ${ }^{(5)}$. The extent of opinion related to issues of relevance to nutrigenomics remains uncertain and requires quantitative investigation.

Qualitative studies have suggested that the general public may have concerns about how genetic information could potentially be used or abused by authorities and other agencies. Before such concerns can be addressed, it is imperative to establish how widespread such views are among the European population. The present large-scale survey has aimed to determine attitudes toward genetic testing and personalised nutrition in a representative sample of the European public. Enquiry has been made into willingness to undergo genetic testing and to subsequently apply such information to dietary intervention. Issues associated with test anxiety and with the handling of genetic information, as well as attitudes toward GM intervention foods, have also been explored.

Previous research in this area has also implied a need to consider the role of knowledge upon attitudes to genetic testing ${ }^{(12,14)}$. The metabolic syndrome is a widespread, pre-disease state, which can be present in varying degrees ${ }^{(15)}$ and which can be prevented and/or treated through dietary means to prevent and reduce chronic disease outcomes such as type 2 diabetes and CHD. The potential for improving public health and reducing health costs by preventing and treating the metabolic syndrome in those genetically predisposed to develop certain aspects of the condition is, therefore, immense ${ }^{(16)}$. Meanwhile, public awareness of the metabolic syndrome and associated co-morbidity appears to be increasing ${ }^{(17)}$. Together, this suggests that the metabolic syndrome could provide a useful model with which to assess the impact of health-related knowledge upon attitudes to nutrigenomics. The present study has considered attitudes toward genetic testing and personalised nutrition in a representative sample of European consumers, taking into account whether they reported one or more signs of the metabolic syndrome.

\section{Methods}

\section{Sampling}

Multi-stage stratified cluster sampling was used with quotas reflecting nationally representative samples of approximately 1000 adults (aged 14 years upwards) recruited in each of six European countries - France, Germany, Great Britain, Italy, Poland and Portugal. These countries were selected for study because they were perceived to be representative of broad geographical regions within the European Union. Each country was divided into a certain number of regions or strata according to population size and density, each containing a certain number of sampling points. The number of sampling points thus varied between countries: France, 108; Germany, 285; Great Britain, 210; Italy, 85; Poland, 200; Portugal, 138. To ensure that the samples from each participating country were as nationally representative as possible, responses were weighted by demographic factors for each sampling point based on the official statistics. The sources were: France, INSEE (National Institute for Statistics and Economic Studies) - Recensement 1999 (Census 1999); Germany, MEDIA ANALYSE 2004; Great Britain, Office of National Statistics; Italy, National Readership Survey; Poland, PESEL State Register - Ministry of Internal Affairs and Administration; Portugal, INE (National Institute of Statistics). Samples in all six countries were representative of each respective national population in terms of age, sex and region. Other sample criteria varied by country according to what information was available. Individuals recruited in France and Great Britain were representative of the national population in terms of occupation. Town size was taken into account when recruiting in Germany, Italy, Poland and Portugal. The resulting sample comprised 5967 European consumers, including 938 individuals in France, 991 in Germany, 1011 in Great Britain, 979 in Italy, 1005 in Poland and 1043 in Portugal (see Table 1).

\section{The questionnaire}

Qualitative studies were carried out in Portugal and the UK to determine consumer perceptions of nutrigenomic intervention. This information guided the development of the survey tool. The process has been described in detail previously ${ }^{(18)}$. The questionnaire was initially developed in English and then translated into each country's language. The translations were verified by the researchers before administration

Table 1. The survey sample by country, age and sex*

\begin{tabular}{|c|c|c|c|c|c|c|}
\hline & \multirow[b]{2}{*}{$n$} & \multicolumn{2}{|c|}{$\operatorname{Sex}(\%)$} & \multicolumn{3}{|c|}{ Age (\%) } \\
\hline & & Male & Female & $14-34$ years & $35-54$ years & $55+$ years \\
\hline France & 938 & 48 & 52 & $33 \cdot 4$ & 33.7 & 32.9 \\
\hline Great Britain & 1011 & $48 \cdot 2$ & $51 \cdot 8$ & $32 \cdot 1$ & $34 \cdot 3$ & $33 \cdot 6$ \\
\hline Germany & 991 & $47 \cdot 8$ & $52 \cdot 2$ & $27 \cdot 7$ & $35 \cdot 1$ & $37 \cdot 2$ \\
\hline Italy & 979 & $48 \cdot 7$ & $51 \cdot 3$ & $33 \cdot 3$ & $36 \cdot 4$ & $30 \cdot 3$ \\
\hline Poland & 1005 & $48 \cdot 8$ & $51 \cdot 2$ & 40 & 34.7 & $25 \cdot 3$ \\
\hline Portugal & 1043 & $47 \cdot 7$ & $52 \cdot 3$ & 34.9 & $32 \cdot 5$ & $32 \cdot 6$ \\
\hline Total & 5967 & $48 \cdot 2$ & $51 \cdot 8$ & $32 \cdot 6$ & $34 \cdot 8$ & $32 \cdot 7$ \\
\hline
\end{tabular}

* Totals may not add up to $100 \%$ owing to missing cases. 
(by piloting it on about thirty respondents in each member state) to ensure that the original meaning had been maintained. Some minor changes were made to the question wording response.

Demographic information collected included region (France, Germany, Italy, Portugal, Poland or Great Britain), sex (male or female), age group (14-24; 25-34; 35-44; $45-54 ; 55-64 ; 65-79 ; 80+$ years), highest level of education achieved (primary, secondary, higher education, still studying or illiterate), working status (working or not working) and, if working, occupation. Samples were recruited to be representative of the population of each of the six countries in terms of social class assessed on criteria specific to each country. Unfortunately, because the criteria for assessing and allocating individuals to different social classes were not consistent between countries, it was not possible to include the variable in the analysis. An initial question then enquired of medical history including any factors associated with the metabolic syndrome such as a high degree of body fat around the middle, stress, high blood pressure, high blood cholesterol and/or high blood sugar. The remainder of the questionnaire comprised close-ended questions which enquired of lifestyle practices, preferences for intervention to prevent and treat the metabolic syndrome, attitudes toward food technological issues and attitudes toward nutrigenomic intervention. An additional optional open-ended item was provided to catalogue specific explanations for attitudes to genetic testing among those sampled in Great Britain, France and Portugal. This analysis reports data pertaining to consumer willingness to undergo genetic testing and attitudes toward genetic testing including nutrigenomic intervention in relation to demographic differences and self-reported evidence of the metabolic syndrome.

\section{Procedure}

Ethical approval was granted by the Office of Research Ethics Committee. Following pilot studies in each of the six countries (France, Italy, Germany, Poland, Portugal and Great Britain) the survey was undertaken as part of an omnibus study carried out by Ipsos MORI (London, UK) during June 2005. Respondents were required to provide signed consent, after which they were given a guarantee of confidentiality. The questionnaire was completed by individual interview in each respondent's home. Demographic information was reported at the start of the interview. The survey was introduced as a survey asking 'questions about health' and interviewers were instructed not to make specific reference to food. Respondents were asked to report if they carried a higher than normal amount of fat around their middle and if they had any history of high blood pressure, high cholesterol, high blood sugar or experienced stress of a degree that interfered with concentration, relaxation or sleep at least once per week. The interviewer then informed the respondent that in future it may be possible to assess your risk of developing late-onset (type 2) diabetes or heart disease with a genetic test of your saliva (by means of a mouth swab). This may allow you to eat foods that are suitable for your genetic profile. Would you personally be likely to (select one of the following): have a test done for general interest only; have a test done specifically so that you can follow a diet tailored to your needs; not have a test done; or don't know?' The respondent was then asked to select from any of eight possible reasons for accepting or rejecting nutrigenomic intervention (see Tables 4 and 5) presented in rotated sequence.

\section{Data analysis}

Data analysis was carried out using the SPSS ${ }^{\circledR}$ for Windows (version 13.0; SPSS Inc., Chicago, IL, USA). Data underwent descriptive analysis. Multinomial logistic regression analysis was then undertaken to determine the degree to which age (continuous variable), sex (dichotomous variable) and having signs of the metabolic syndrome (fat around the middle, high perceived stress, high blood cholesterol, high blood pressure and/or high blood sugar) predicted attitudes to genetic testing (responses to 'have a test done for general interest' were compared with 'have a test done to follow a personalised diet', 'not have a test done' and 'don't know') and nutrigenomic intervention (responses to 'good to know if you are genetically at risk' were compared with 'worry how test's information might be used', 'worry that intervention foods might be GM' and 'not interested'). Open-ended responses were content analysed.

\section{Results}

\section{Sample description}

A total of 5967 Europeans completed the questionnaire. Sample structure in each country by sex, age, working status and education level is shown in Table 1 . Sex ranged between $52 \cdot 3$ and $51.2 \%$ female between countries. Poland had the youngest population with $40 \%$ aged between 14 and 34 years of age and Germany had the oldest population with $37.2 \%$ aged over 55 years. A descriptive overview of responses to the questionnaire has been published elsewhere ${ }^{(17)}$.

\section{Self-reported signs of the metabolic syndrome}

One fifth of the sample $(20 \%)$ reported having a high proportion of fat around the middle, $15 \%$ had a history of high blood pressure, $12 \%$ high cholesterol and $5 \%$ high blood sugar (Table 2). Nearly one-third (30\%) perceived themselves to suffer from stress at least once per week. Of the six countries, the highest reported incidence of central obesity was in Great Britain (29\%). Portugal had the highest reported incidence of high blood pressure $(22 \%)$, high cholesterol (21\%) and high blood sugar $(8 \%$ ) (Table 2). Females reported signs of the metabolic syndrome more frequently than males (Table 2). Reported signs of the metabolic syndrome became more frequent with age (Table 2). Those in the $65+$ years age group were least likely to report stress (Table 2).

\section{Willingness to undergo genetic testing and personalised nutrition: demographic factors}

More than a third of the sample $(38.8 \%)$ reported a willingness to undergo genetic testing for general interest, and $27.8 \%$ to follow a diet tailored to their needs (Table 3). Nearly a quarter $(22.1 \%)$ indicated that they would not be willing to have a genetic test and a further $11.3 \%$ did not 
Table 2. Self-reported signs of the metabolic syndrome across six European countries, sex and age group ( $n$ 5967)

\begin{tabular}{|c|c|c|c|c|c|}
\hline & High blood cholesterol (\%) & High blood pressure (\%) & Central obesity (\%) & High blood sugar (\%) & Stress (\%) \\
\hline \multicolumn{6}{|l|}{ Country } \\
\hline France & $12 \cdot 6$ & $12 \cdot 5$ & $16 \cdot 4$ & $5 \cdot 3$ & $35 \cdot 5$ \\
\hline Great Britain & $15 \cdot 2$ & $20 \cdot 7$ & $33 \cdot 1$ & $6 \cdot 8$ & $32 \cdot 3$ \\
\hline Germany & $11 \cdot 2$ & $15 \cdot 9$ & $19 \cdot 7$ & $6 \cdot 5$ & $18 \cdot 5$ \\
\hline Italy & $12 \cdot 8$ & $15 \cdot 8$ & $19 \cdot 9$ & $4 \cdot 0$ & $34 \cdot 6$ \\
\hline Poland & $6 \cdot 9$ & $11 \cdot 8$ & $14 \cdot 0$ & 3.9 & $17 \cdot 3$ \\
\hline \multicolumn{6}{|c|}{ Age group (years) } \\
\hline $14-24$ & $2 \cdot 4$ & $3 \cdot 0$ & $9 \cdot 0$ & $2 \cdot 4$ & $22 \cdot 5$ \\
\hline $25-34$ & $4 \cdot 1$ & $4 \cdot 0$ & 11.4 & 1.5 & $30 \cdot 5$ \\
\hline $35-44$ & $7 \cdot 3$ & $7 \cdot 2$ & $18 \cdot 8$ & $4 \cdot 0$ & $34 \cdot 4$ \\
\hline $45-54$ & $14 \cdot 8$ & $15 \cdot 8$ & 24.5 & $4 \cdot 4$ & $38 \cdot 1$ \\
\hline $55-64$ & 22.9 & $29 \cdot 0$ & $29 \cdot 5$ & $10 \cdot 2$ & $32 \cdot 7$ \\
\hline $65+$ & $30 \cdot 1$ & $41 \cdot 5$ & 28.9 & $13 \cdot 1$ & $23 \cdot 7$ \\
\hline \multicolumn{6}{|l|}{ Sex } \\
\hline Female & $13 \cdot 9$ & $17 \cdot 6$ & $22 \cdot 0$ & 5.9 & 34.4 \\
\hline Total & $13 \cdot 5$ & $16 \cdot 7$ & $20 \cdot 3$ & 5.9 & $30 \cdot 8$ \\
\hline
\end{tabular}

* Totals may not add up to $100 \%$ owing to missing cases.

know whether or not they would have a test. The Portuguese sample had the highest proportion who indicated willingness to undergo genetic testing $(48.5 \%)$. More than a third of those in France $(44.3 \%)$, Great Britain $(37.6 \%)$, Germany $(35.1 \%)$ and Italy $(34.3 \%)$ indicated that they would be willing to undergo genetic testing. More than a third of those in Great Britain $(38.7 \%)$ and Italy $(38.3 \%)$ would do so to follow a personalised diet (Table 3). Those in the $65+$ years age group most frequently $(55 \cdot 2 \%)$ indicated willingness to undergo genetic testing and for the purpose of following a personalised diet $(50 \%)$.

\section{Willingness to undergo genetic testing and personalised} nutrition: self-reported metabolic syndrome

More than a third of respondents $(38.8 \%)$ indicated willingness to undergo genetic testing for general interest, while $27.8 \%$ would do so for the purpose of following a personalised diet. Table 4 shows the percentage of those reporting high stress, central obesity, high blood pressure and high blood cholesterol who indicated that they would be willing to undergo genetic testing for general interest and for the purpose of following a personalised diet. More than one-third $(40.8 \%)$ of those reporting high stress indicated that they would be willing to have a genetic test (Table 4).

\section{Multinomial logistic regression analysis}

Multinomial regression analysis was conducted to determine the degree to which someone's awareness that they have signs of the metabolic syndrome predicted willingness to undergo genetic testing and/or follow a personalised diet. The group who indicated that they were willing to undergo a test for general interest were compared with those who would have a test done to follow a personalised diet, those who were unwilling to have a test and those who did not know. Those endorsing the statement 'have a test done to follow a personalised diet' were 1.35 times more likely to report central obesity, 1.271 times more likely to report high blood cholesterol and 1.226 times more likely to perceive themselves to have high levels of stress than those who would merely 'have a test done for general interest' (Table 5). Those who indicated that they would 'not have a test done' were more likely than those who 'would have a test done for general interest' to be male and were less likely to have reported central obesity. Those who did not know whether or not they wanted a genetic test were less likely than those who 'would have a test done for general interest' to report high stress.

\section{Attitudes to genetic testing and personalised nutrition: self- reported metabolic syndrome}

Respondents were asked to indicate the reasons why they would or would not be willing to undergo genetic testing. The majority $(53.4 \%)$ agreed that it would be good to know if they were genetically at risk. The proportion of those reporting signs of the metabolic syndrome who indicated concern about how such information would be used, whether intervention foods would be GM and other reasons for refusing genetic testing are shown on Table 4.

\section{Multinomial logistic regression analysis}

Multinomial regression analysis was carried out to determine the degree to which someone's awareness that they have signs of the metabolic syndrome predicted attitudes toward genetic testing and personalised nutrition. Items enquiring as to concern over how information might be used (by insurers, employers or police authorities) were amalgamated for the purpose of this analysis. The group who indicated that 'it's good to know if you are genetically at risk' were compared with those who indicated that they would 'worry how the test information might be used', 'worry that foods might be GM' or other reasons ('changing lifestyle is enough', 'live life to the full', not interested'). Those who indicated that 
Table 3. Attitudes toward nutrigenomics across six European countries, sex and age group ( $n$ 5967)

\begin{tabular}{|c|c|c|c|c|c|c|c|c|c|c|}
\hline & $\begin{array}{l}\text { Have a test } \\
\text { done for } \\
\text { general } \\
\text { interest (\%) }\end{array}$ & $\begin{array}{l}\text { Have a test } \\
\text { done to follow } \\
\text { a personalised } \\
\text { diet }(\%)\end{array}$ & $\begin{array}{l}\text { It is good to } \\
\text { know if you } \\
\text { are genetically } \\
\text { at risk }(\%)\end{array}$ & $\begin{array}{l}\text { Changing my } \\
\text { lifestyle is } \\
\text { enough to get } \\
\text { benefit (\%) }\end{array}$ & $\begin{array}{l}\text { Live life to the } \\
\text { full and not } \\
\text { worry about } \\
\text { tests }(\%)\end{array}$ & $\begin{array}{l}\text { Not interested } \\
\text { in eating food } \\
\text { based on my } \\
\text { genetic profile } \\
(\%)\end{array}$ & $\begin{array}{l}\text { I worry that } \\
\text { the food may } \\
\text { be GM (\%) }\end{array}$ & $\begin{array}{l}\text { I worry how } \\
\text { the test } \\
\text { information } \\
\text { might be used } \\
\text { by insurers } \\
(\%)\end{array}$ & $\begin{array}{l}\text { I worry how } \\
\text { the test } \\
\text { information } \\
\text { might be used } \\
\text { by employers } \\
(\%)\end{array}$ & $\begin{array}{l}\text { I worry how } \\
\text { the test } \\
\text { information } \\
\text { might be used } \\
\text { by authorities } \\
\text { or police }(\%)\end{array}$ \\
\hline \multicolumn{11}{|l|}{ Country } \\
\hline France & $44 \cdot 3$ & $29 \cdot 3$ & $55 \cdot 2$ & $6 \cdot 8$ & 4.9 & $6 \cdot 8$ & $6 \cdot 1$ & $2 \cdot 8$ & $2 \cdot 3$ & $2 \cdot 1$ \\
\hline Great Britain & $37 \cdot 6$ & $38 \cdot 7$ & 53.9 & $5 \cdot 9$ & $3 \cdot 7$ & $3 \cdot 3$ & $2 \cdot 6$ & 1.2 & 0.9 & 1.0 \\
\hline Germany & $35 \cdot 1$ & $13 \cdot 4$ & $40 \cdot 2$ & $15 \cdot 8$ & $8 \cdot 1$ & $12 \cdot 1$ & $12 \cdot 7$ & $7 \cdot 7$ & 2.5 & $6 \cdot 8$ \\
\hline Italy & 34.3 & 38.3 & $61 \cdot 2$ & $6 \cdot 2$ & $6 \cdot 3$ & 3.9 & $10 \cdot 2$ & 1.3 & 1.3 & 1.3 \\
\hline Poland & $32 \cdot 9$ & $21 \cdot 0$ & 43.5 & $5 \cdot 2$ & $6 \cdot 7$ & $5 \cdot 1$ & $2 \cdot 3$ & $1 \cdot 3$ & $1 \cdot 3$ & 1.6 \\
\hline Portugal & 48.5 & $26 \cdot 1$ & $66 \cdot 1$ & $2 \cdot 9$ & $3 \cdot 1$ & $3 \cdot 7$ & $6 \cdot 8$ & 2.9 & $2 \cdot 8$ & 1.3 \\
\hline \multicolumn{11}{|c|}{ Age group (years) } \\
\hline $14-24$ & $45 \cdot 0$ & 24.5 & 54.4 & $5 \cdot 7$ & $5 \cdot 3$ & 5.5 & $6 \cdot 0$ & $2 \cdot 3$ & $2 \cdot 3$ & 1.4 \\
\hline $25-34$ & $41 \cdot 8$ & 28.5 & 56 & 7.8 & 4.8 & 4.7 & 7.9 & 3.4 & 3.0 & $2 \cdot 6$ \\
\hline $35-44$ & 40.9 & $27 \cdot 9$ & $55 \cdot 1$ & $7 \cdot 2$ & $6 \cdot 4$ & 5.5 & $6 \cdot 3$ & $3 \cdot 8$ & $3 \cdot 3$ & $3 \cdot 0$ \\
\hline $45-54$ & 37.9 & $30 \cdot 1$ & 56 & $6 \cdot 4$ & 4.5 & $6 \cdot 9$ & 7.9 & $3 \cdot 3$ & 2.5 & $3 \cdot 1$ \\
\hline $55-64$ & $35 \cdot 2$ & 29.5 & $52 \cdot 8$ & 7.5 & $5 \cdot 0$ & $6 \cdot 4$ & 6.5 & $2 \cdot 8$ & $2 \cdot 2$ & $2 \cdot 6$ \\
\hline $65+$ & $55 \cdot 2$ & $50 \cdot 0$ & $46 \cdot 2$ & 7.9 & $6 \cdot 4$ & $5 \cdot 7$ & $6 \cdot 0$ & 1.5 & $1 \cdot 3$ & 1.4 \\
\hline \multicolumn{11}{|l|}{ Sex } \\
\hline Male & $38 \cdot 3$ & $26 \cdot 6$ & 51.8 & $7 \cdot 0$ & 6.4 & $6 \cdot 1$ & $6 \cdot 7$ & 3.0 & 2.9 & $2 \cdot 9$ \\
\hline Female & $39 \cdot 3$ & 28.8 & 54.8 & $7 \cdot 2$ & 4.5 & 5.5 & $6 \cdot 8$ & $2 \cdot 7$ & $2 \cdot 0$ & 1.9 \\
\hline Total & $38 \cdot 8$ & $27 \cdot 8$ & $53 \cdot 4$ & $7 \cdot 1$ & $5 \cdot 4$ & $5 \cdot 8$ & $6 \cdot 8$ & $2 \cdot 8$ & $2 \cdot 4$ & $2 \cdot 3$ \\
\hline
\end{tabular}

* Totals may not add up to $100 \%$ owing to missing cases. 
Table 4. Attitudes toward nutrigenomics and self-reported metabolic syndrome*

\begin{tabular}{|c|c|c|c|c|c|c|}
\hline & $\begin{array}{c}\text { High blood } \\
\text { cholesterol } \\
(\%)\end{array}$ & $\begin{array}{l}\text { High blood } \\
\text { pressure } \\
(\%)\end{array}$ & $\begin{array}{c}\text { High } \\
\text { blood sugar } \\
(\%)\end{array}$ & $\begin{array}{c}\text { Central } \\
\text { obesity } \\
(\%)\end{array}$ & $\begin{array}{l}\text { High stress } \\
\qquad(\%)\end{array}$ & $\begin{array}{l}\text { No signs } \\
(\%)\end{array}$ \\
\hline$n$ & 767 & 968 & 336 & 1172 & 1763 & 2840 \\
\hline Have a test done for general interest & $36 \cdot 5$ & $36 \cdot 8$ & $32 \cdot 7$ & $37 \cdot 8$ & $40 \cdot 8$ & $39 \cdot 4$ \\
\hline Have a test done to follow a personalised diet & $38 \cdot 1$ & $33 \cdot 5$ & $37 \cdot 2$ & 38.4 & $35 \cdot 5$ & $22 \cdot 1$ \\
\hline Not have a test done & $16 \cdot 3$ & $19 \cdot 0$ & $19 \cdot 9$ & $16 \cdot 0$ & $16 \cdot 0$ & $25 \cdot 7$ \\
\hline Don't know whether to have a test & $9 \cdot 1$ & $10 \cdot 7$ & $10 \cdot 1$ & $7 \cdot 8$ & $7 \cdot 7$ & $12 \cdot 8$ \\
\hline It is good to know if you are genetically at risk & $15 \cdot 1$ & $17 \cdot 5$ & 5.9 & $22 \cdot 0$ & $34 \cdot 1$ & $49 \cdot 5$ \\
\hline Changing my lifestyle is enough to get benefit & $10 \cdot 1$ & $15 \cdot 1$ & $6 \cdot 1$ & $17 \cdot 3$ & $27 \cdot 0$ & 7.5 \\
\hline Live life to the full and not worry about tests & $9 \cdot 7$ & $15 \cdot 3$ & $4 \cdot 6$ & $16 \cdot 6$ & $21 \cdot 7$ & $6 \cdot 0$ \\
\hline $\begin{array}{l}\text { Not interested in eating food based on } \\
\text { my genetic profile }\end{array}$ & $10 \cdot 1$ & $12 \cdot 9$ & $5 \cdot 0$ & $16 \cdot 4$ & $22 \cdot 7$ & $7 \cdot 1$ \\
\hline I worry that the food may be GM & $11 \cdot 6$ & $15 \cdot 6$ & $6 \cdot 4$ & $21 \cdot 0$ & $30 \cdot 6$ & $7 \cdot 0$ \\
\hline $\begin{array}{l}\text { I worry how the test information might } \\
\text { be used by insurers }\end{array}$ & $15 \cdot 5$ & $10 \cdot 2$ & $3 \cdot 6$ & $18 \cdot 7$ & $34 \cdot 1$ & 2.9 \\
\hline $\begin{array}{l}\text { I worry how the test information might } \\
\text { be used by employers }\end{array}$ & $12 \cdot 0$ & $14 \cdot 8$ & 3.5 & $16 \cdot 8$ & 31.5 & $2 \cdot 6$ \\
\hline $\begin{array}{l}\text { I worry how the test information might } \\
\text { be used by authorities or police }\end{array}$ & $11 \cdot 5$ & $11 \cdot 8$ & $5 \cdot 2$ & $19 \cdot 1$ & $26 \cdot 5$ & $2 \cdot 4$ \\
\hline
\end{tabular}

${ }^{\star}$ Totals may not add up to $100 \%$ owing to missing cases.

they would 'worry that the foods might be GM' were less likely than those endorsing the statement 'it's good to know if you are genetically at risk' to report high blood cholesterol. Those who endorsed 'other' reasons for not wanting to be genetically tested (for example, not interested in having a test) were less likely than those who endorsed the statement 'it's good to know if you are genetically at risk' to report central obesity and/or stress (Table 6).

\section{Responses to open-ended question}

A total of 250 responses were made to the open-ended question enquiring of reasons why individuals would be willing or unwilling to undergo genetic testing. Reasons given for having a test included: to get healthier/reduce risk $(18.8 \%)$; to make dietary changes $(14.8 \%)$; curiosity/interest $(10.8 \%)$; having a health problem/medical advice $(7.6 \%)$; family history $(6 \%)$; to take control/make choices $(2.8 \%)$. Reasons for not having a test included: sceptical/mistrust/unproven efficacy (6\%); age (too young or too old) $(5.2 \%)$; no need ( $5.2 \%)$; don't want to know/ 'ignorance is bliss' $(3.6 \%)$; eating healthily is enough $(3.2 \%)$; don't want to change diet $(3.2 \%)$; GM $(2 \%)$. The remaining responses were provisional: if information kept private $(1.2 \%)$; uncategorised/other $(6 \cdot 8 \%)$.

\section{Discussion}

This appears to be the first large-scale representative survey carried out on a European-wide basis to have included, among issues investigated, attitudes toward genetic testing and personalised nutrition. Public acceptance of nutrigenomic intervention and how issues of public concern are dealt with are considered important determinants of the future success of this novel approach to dietary health promotion ${ }^{(5)}$. Reported willingness to undergo genetic testing for the purpose of personalised nutrition varied across the six countries, ranging from $13.4 \%$ in Germany to $38.7 \%$ in Great Britain. There was also some variation across age group. Willingness to undergo genetic testing for general interest was lowest among the 55-64 years age group $(35 \cdot 2 \%)$ and highest in the over 65 years age group $(55 \cdot 2 \%)$. Nevertheless, similar to figures found in the $\mathrm{USA}^{(12)}$ and among patient groups in the Netherlands ${ }^{(14)}$, as many as $22 \%$ of consumers in this survey sample indicated that they would not avail of the opportunity to have a genetic test. In view of emerging evidence to suggest that stress may precipitate the metabolic syndrome $^{(19)}$, a measure of subjective stress was included among health-related factors and as an indication of psychological wellbeing. Of those reporting a health problem, those

Table 5. Willingness to undergo genetic testing and personalised nutrition and self-reported metabolic syndrome: multinomial logistic regression analysis

\begin{tabular}{|c|c|c|c|c|c|c|c|c|c|}
\hline & \multicolumn{3}{|c|}{$\begin{array}{l}\text { 'Have test done to follow personal- } \\
\text { ised diet' compared with 'have test } \\
\text { for general interest' }\end{array}$} & \multicolumn{3}{|c|}{$\begin{array}{l}\text { 'Not have a test done' compared } \\
\text { with 'have test done for general } \\
\text { interest' }\end{array}$} & \multicolumn{3}{|c|}{$\begin{array}{l}\text { 'Don't know' compared with 'have } \\
\text { test done for general interest' }\end{array}$} \\
\hline & B & $\mathrm{SE}$ & $\operatorname{Exp}(B)$ & B & $\mathrm{SE}$ & $\operatorname{Exp}(B)$ & $B$ & $\mathrm{SE}$ & $\operatorname{Exp}(\mathrm{B})$ \\
\hline Sex & -0.026 & 0.068 & 0.974 & -0.166 & 0.072 & $0.847^{\star}$ & 0.017 & 0.095 & 1.017 \\
\hline High cholesterol & 0.240 & 0.108 & $1 \cdot 271^{*}$ & -0.160 & 0.131 & 0.852 & -0.173 & 0.171 & 0.841 \\
\hline High blood pressure & 0.040 & 0.104 & 1.041 & 0.106 & 0.117 & 1.112 & 0.228 & 0.148 & 1.256 \\
\hline Central obesity & 0.300 & 0.087 & $1 \cdot 350^{\star \star}$ & -0.318 & 0.107 & $0.728^{\star \star}$ & -0.237 & 0.138 & 0.789 \\
\hline High blood sugar & 0.246 & 0.153 & 1.278 & 0.292 & 0.178 & 1.339 & 0.082 & 0.241 & 1.085 \\
\hline Stress & 0.204 & 0.073 & $1 \cdot 226^{\star \star}$ & -0.451 & 0.086 & 0.637 & -0.518 & 0.115 & $0.596^{\star \star}$ \\
\hline
\end{tabular}

${ }^{*} P<0.05,{ }^{* *} P<0.01$ 
Table 6. Attitudes toward nutrigenomic intervention and self-reported metabolic syndrome: multinomial logistic regression analysis

\begin{tabular}{|c|c|c|c|c|c|c|c|c|c|}
\hline & \multicolumn{3}{|c|}{$\begin{array}{l}\text { 'Worry how test information } \\
\text { might be used' compared with } \\
\text { 'it's good to know genetic risk' }\end{array}$} & \multicolumn{3}{|c|}{$\begin{array}{l}\text { 'Worry that foods might be GM' } \\
\text { compared with 'it's good to } \\
\text { know genetic risk' }\end{array}$} & \multicolumn{3}{|c|}{$\begin{array}{l}\text { 'Not interested in having gen- } \\
\text { etic test' compared with 'it's } \\
\text { good to know genetic risk' }\end{array}$} \\
\hline & B & SE & $\operatorname{Exp}(B)$ & B & SE & $\operatorname{Exp}(B)$ & B & SE & $\operatorname{Exp}(B)$ \\
\hline Sex & -0.226 & 0.127 & 0.798 & 0.056 & 0.123 & 1.058 & -0.101 & 0.084 & 0.904 \\
\hline High cholesterol & 0.123 & 0.210 & $1 \cdot 131$ & -0.484 & 0.227 & $0.616^{*}$ & -0.231 & 0.149 & 0.794 \\
\hline High blood pressure & -0.359 & 0.218 & 0.698 & -0.040 & 0.195 & 0.961 & 0.032 & 0.134 & 1.033 \\
\hline Central obesity & -0.117 & 0.177 & 0.890 & 0.051 & 0.163 & 1.052 & -0.257 & 0.121 & $0.773^{\star}$ \\
\hline High blood sugar & -0.198 & 0.338 & 0.821 & 0.328 & 0.273 & $1 \cdot 388$ & 0.131 & 0.204 & $1 \cdot 140$ \\
\hline Stress & -0.061 & $0 \cdot 140$ & 0.941 & -0.160 & 0.136 & 0.852 & -0.432 & 0.099 & $0.649^{\star \star}$ \\
\hline
\end{tabular}

${ }^{*} P<0.05,{ }^{* *} P<0.01$

who reported high levels of perceived stress appeared most positive about receiving genetic profiling information.

Recent initiatives to increase awareness of the detrimental impact of obesity upon health and to promote screening for factors associated with the metabolic syndrome have brought about a situation whereby a sizable proportion of the European public are aware that they may have a potential health problem. Individuals who were aware that they had signs of the metabolic syndrome appeared to view genetic testing and personalised nutrition relatively favourably. Those who indicated reluctance to undergo genetic testing were less likely to report having any signs of the metabolic syndrome. Previous survey research carried out in the Netherlands ${ }^{(13,14)}$ has indicated more positive attitudes to genetic testing where there is potential for individuals to use the information for their own health benefit. It was, therefore, not unexpected to find that respondents to this survey who reported a history of high blood cholesterol levels, central obesity or high levels of stress were more likely to indicate willingness to have a genetic test, not just for general interest, but also to act upon the results for the purpose of following a personalised diet.

Individuals who knew that they had a potential health problem associated with the metabolic syndrome also had relatively favourable attitudes to personalised nutrition. Individuals who reported central obesity and stress were less likely than those who did not report such factors to cite 'other' reasons for not having a genetic test such as 'not interested in eating food based on my genetic profile' or 'changing my lifestyle is enough to get benefit'. Those most likely to agree that 'it's good to know one's genetic risk' and least likely to indicate concern as to whether potential intervention foods were GM tended to be those who knew they had a high blood cholesterol level. Together, these findings could suggest that knowledge of genetic-lifestyle-disease interactions is increasing and along with it a willingness among the public to tailor lifestyle practices to maximise health, especially among those who know that they carry risk for chronic disease.

Not all of our findings back up those of previous studies. Qualitative research carried out in the $\operatorname{USA}^{(7,8)}$ and in the $\mathrm{UK}^{(10,11)}$ has suggested that barriers to the uptake of genetic testing include concern as to how such information could be misused or exploited by certain authorities. Our data, in contrast, have indicated that, at the time this survey was conducted, there was a relative lack of concern among the public as to how genetic information would be handled or applied in practice. Although these data suggest some unwillingness among the general European public to accept nutrigenomic intervention, only a small minority of those who would not have a genetic test, equivalent to $2-3 \%$ of the entire sample, indicated that they were concerned as to how such information might be used by the authorities or misused by other agencies. More astonishing, in the light of abundant social research indicating that the European public are wary of GM foods ${ }^{(20)}$, was that only a minority $(6.8 \%)$ of those who would not undergo genetic testing indicated concern that potential dietary intervention foods could be GM. Another novel finding was that those who reported that they were unwilling to have a genetic test were more likely to be male than those who were willing. What few survey studies exist ${ }^{(12,14)}$ have not found sex differences in willingness to undergo genetic testing. These data, nevertheless, imply that intervention to encourage uptake of genetic testing and healthy dietary practices in European consumers would do well to specifically target males.

The descriptive and correlational nature of the data analyses may have limited the degree to which conclusions can be drawn from the present study. It is conceivable that awareness of the metabolic syndrome and positive attitudes toward nutrigenomics are similarly motivated. Individuals who have sought knowledge of their health status, possibly because there has been a family history of chronic disease, may also be likely to seek screening for genetic propensity for disease. Responses to the open-ended questions would appear to back up such an explanation. The most common reasons offered for seeking genetic testing were concerned with reducing health risk and adapting lifestyle, or where there was a personal or family history of chronic disease. It is nevertheless encouraging that a substantial proportion of the European public are both aware of their health status and amenable to nutrigenomic intervention to avert any disease risk. It could also be argued that the degree to which these data can be relied upon has been limited by the self-reported nature of the health-related information. Given the data were self-reported and therefore relied upon respondents being aware that they had a health problem, the actual incidence of the metabolic syndrome is likely to have been higher in this population. Any lack of accuracy in these data, however, has been compensated for by the representative nature and large size of the sample. Indeed, self-reported health-related information could be considered especially meaningful in the context of health promotion. Population-based interventions, in order to effectively change behaviour, require the target population 
to be aware they have a potential for disease. It has been argued that there is a need for research in this area to address the role that knowledge plays in determining attitudes to genetic testing ${ }^{(12)}$. The metabolic syndrome appears to have provided a useful and valid reference point from which to research the influence of knowledge of health status upon attitudes toward genetically appropriate nutritional health intervention in a population study. These data imply that knowledge of health status exerts a positive influence upon attitudes toward genetic testing and personalised nutrition.

\section{Conclusions}

There is an apparent dearth of research that has enquired into views related to genetic testing and no quantitative studies that have specifically considered attitudes toward nutrigenomic intervention. Insight into public opinion of genetic testing and personalised nutrition is imperative for the promotion of selective dietary therapies. These data imply a readiness, particularly in those among the European public who are aware that they may be at risk of chronic disease, to accept this new technology and to apply it to their diet to improve their health. Individuals who reported signs of the metabolic syndrome appear less concerned than those who do not about how genetic information could be misused by authorities or whether intervention foods contain GM ingredients. These findings are encouraging for the development of novel dietary interventions combining genetics and nutrition to prevent and/ or treat the metabolic syndrome, type 2 diabetes and CHD in the European population provided effective policies are put in place to control the storage and use of such information and that adequate public engagement occurs to inform appropriate delivery of related services ${ }^{(3)}$ and products ${ }^{(4)}$.

\section{Acknowledgements}

The present study was completed on behalf of the Lipgene Consortium and funded under the European Union 6th Framework Food Quality and Safety Programme (code FOOD-CT2003-505944). Survey fieldwork was subcontracted to Ipsos MORI (London, UK). The authors are aware of no personal, commercial, political, academic or financial conflict of interest that could have influenced the reporting of this research. B. J. S.-K. designed the study and wrote the paper. B. P. B. provided statistical support. H. J. P. supervised data collection and undertook data analysis. S. G. carried out the preliminary data analysis. S. P. co-supervised data collection. M. D. V. de A. designed and administered the project work package. M. G. coordinated the project.

\section{References}

1. German JB \& Watkins SM (2004) Metabolic assessment - a key to nutritional strategies for health. Trends Food Sci Technol 15, 541-549.

2. Castle D, Cline C, Daar AS, Tsamis C \& Singer PA (2006) Science, Society and the Supermarket: the Opportunities and Challenges of Nutrigenomics. New Jersey: John Wiley, Sons.
3. Castle D \& Ries NM (2007) Ethical, legal and social issues in nutrigenomics: the challenges of regulating service delivery and building health professional capacity. Mutat Res 622, $138-143$

4. Moskowitz HR, German JB \& Saguy IS (2005) Unveiling health attitudes and creating good-for-you foods: the genomics metaphor, consumer innovative web-based technologies. Crit Rev Food Sci Nutr 45, 165-191.

5. Castle D (2007) Public attitudes toward nutrigenomics. Issues in ethics. Implications for the future. Nutrigenomics and Beyond: Informing the Future - Workshop Summary. Institute for the Future. http://books.nap.edu/openbook.php?record_id $=11845$ \&page $=41$

6. Ronteltap A, van Trijp JCM \& Renes RJ (2007) Expert views on critical success and failure factors for nutrigenomics. Trends Food Sci Technol 18, 189-200.

7. Rose AL, Peters N, Shea JA \& Armstrong K (2005) Attitudes and misconceptions about predictive genetic testing for cancer risk. Community Genet 8, 145-151.

8. Catz DS, Green N, Tobin JN, Lloyd-Puryear MA, Kyler P, Umemoto A, Cernoch J, Brown R \& Wolman F (2005) Attitudes about genetics in underserved, culturally diverse populations. Community Genet 8, 161-172.

9. Bates BR, Lynch JA, Bevan JL \& Condit CM (2005) Warranted concerns, warranted outlooks: a focus group study of public understandings of genetic research. Soc Sci Med 60, 331-344.

10. Petersen A (2005) Securing our genetic health: engendering trust in UK Biobank. Sociol Health Illn 27, 271-292.

11. Skirton H, Frazier LQ, Calvin AO \& Cohen MZ (2006) A legacy for the children - attitudes of older adults in the United Kingdom to genetic testing. J Clin Nurs 15, 565-573.

12. Wang SS, Fridinger F, Sheedy KM \& Khoury MJ (2001) Public attitudes regarding the donation and storage of blood specimens for genetic research. Community Genet 4, 18-26.

13. Henneman L, Timmermans DRM \& van der Wal G (2006) Public attitudes toward genetic testing: perceived benefits and objections. Genet Test 10, 139-145.

14. Morren M, Rijken M, Baanders AN \& Bensing J (2007) Perceived genetic knowledge, attitudes toward genetic testing and the relationship between these among patients with chronic disease. Patient Educ Couns 65, 197-204.

15. Kinnunen ML, Kokkonen M, Kaprio J \& Pulkkinen L (2005) The association of emotion regulation and dysregulation with the metabolic syndrome factor. J Psychosom Res 58, 513-521.

16. Butriss JL (2006) Diet-gene interactions and current EU research: something for everybody!. Nutr Bull 31, 65-68.

17. de Almeida MDV, Pinhao S, Stewart-Knox B, Parr HJ \& Gibney MJ (2006) An overview of findings from a six-country European survey on consumer attitudes to the metabolic syndrome, genetics in nutrition and potential agro-food technologies. Nutr Bull 31, 139-246.

18. de Almeida MDV, Pinhao S, Stewart-Knox B, Parr HJ \& Gibney MJ (2006) A six-country survey on consumer attitudes to the metabolic syndrome, genetics in nutrition and potential agro-food technologies: questionnaire design methodology. Nutr Bull 31, 138-144.

19. Fan A, Dwyer K \& Dwyer J (2003) Chronic stress is related to susceptibility of metabolic syndrome through elevating sympathetic activity in middle-aged adults. The Los Angeles Atherosclerosis Study. Atheroscler Suppl 4, 87.

20. European Commission (2006) Risk Issues. Special Eurobarometer 238/Wave 64.1- TNS Opinion \& Social. 